\title{
Fictive motion as cognitive simulation
}

\author{
TEENIE MATLOCK \\ Stanford University, Stanford, California
}

\begin{abstract}
Sentences such as The road runs through the valley and The mountain range goes from Canada to Mexico include a motion verb but express no explicit motion or state change. It is argued that these sentences involve fictive motion, an implicit type of motion. But do people trying to understand these sentences mentally simulate motion? This question was addressed in four experiments. In each, participants read a story about travel—for instance, fast versus slow, short versus long distance, and easy versus difficult terrain - and then made a timed decision about a fictive motion sentence. Overall, latencies were shorter after they had read about fast travel, short distances, and easy terrains. Critically, the effect did not arise with nonfictive motion target sentences (e.g., The road is in the valley), as was demonstrated in three control studies. The results suggest that the processing of fictive motion includes mental simulation.
\end{abstract}

In everyday thought, people mentally simulate all sorts of actions. They imagine themselves and others running on trails, driving cars, and jumping out of planes. They imagine nonvolitional agents in action, such as leaves falling from trees and waves crashing on the shore. People also imagine actions they have never witnessed, such as King Kong climbing a skyscraper or a flying saucer zipping across the sky. They even imagine abstract geometrical shapes rotating in space. The question addressed here is the extent to which mentally simulated motion generalizes. Does it occur with figurative language-namely, sentences such as The road goes through the desert or The fence runs along the property line? If it does, we can conclude that mental simulation is a fundamental part of everyday thought.

\section{Mental Simulation Is Ubiquitous}

Much research supports the hypothesis that people mentally simulate actions in everyday thought. Some studies focus on categorization and recall, and others focus on literal language comprehension. In a study by Barsalou (1999a), participants did basic motor actions while attempting to categorize objects. They were quicker to categorize the object when the action was congruent with it (e.g., a turning motion with faucet). Similar results were obtained in recall. People were quicker to recall sock, sweater, and other properties associated with drawer when they pulled their hands toward the body (see Barbey, Simmons, Ruppert, \& Barsalou, 2002). In a study by Glenberg

I thank Nicole Albert, Jeremy Elman, Kat Firme, Sydney Gould, Krysta Hayes, and John Nolan for running participants and Paul Maglio for writing computer scripts. I also thank Herbert Clark, Raymond Gibbs, Jr., Daniel Schwartz, Michael Spivey, and Leonard Talmy for sharing many useful insights, as well as Arthur Glenberg, Lee Osterhout, Rolf Zwaan, and an anonymous reviewer for commenting on earlier drafts. Correspondence concerning this article should be addressed to T. Matlock, Psychology Department, Stanford University, Bldg. 420, Stanford, CA 94305-2130 (e-mail: tmatlock@psych.stanford.edu). and Kaschak (2002), people were quicker to judge direction of movement communicated in imperative statements, such as Open the drawer or Close the drawer, when they made a hand movement that was consistent with the direction asserted in the sentence (toward or away from the body). The same action compatibility effect was demonstrated with sentences about abstract transfer, such as Liz told you the story, in which intangible entities (e.g., story) are transferred from one agent to another.

Mentally enacting movement is also known to influence reasoning. In a study on solving everyday physics problems by Schwartz and Black (1999), people were more accurate at estimating when water would pour out of a glass after having imagined tilting the glass. They were also more accurate when they held an empty glass and actually tilted it (Schwartz, 1999). In a study on temporal reasoning by Boroditsky and Ramscar (2002), people were more likely to adopt a time-moving perspective and view time as "moving" forward when they had imagined being pulled toward a stationary landmark. In contrast, they were more likely to adopt an ego-moving perspective and view themselves as moving through time after they had imagined moving toward a landmark (see also Boroditsky, 2000; Clark, 1973).

Research on spatial models and situation models also provides evidence for simulated motion. In some cases, models are constructed from the examination of maps and other spatial depictions, and in others, they are constructed from the reading of text. Of course, representations constructed from the reading of text may involve less spatial imagery than representations constructed from the memorization of maps or other spatial layouts (see Zwaan \& van Oostendorp, 1993, for a discussion), but in both cases, people are able to imagine scenes and simulate motion. In constructing a model, people take a particular perspective, either an objective perspective (e.g., a bird's eye view) or a subjective perspective (e.g., a protagonist's viewpoint), and they imagine themselves or others moving (Tversky, 1996, 2000). They also keep track of where 
objects are by anchoring them to other objects (e.g., Bower \& Morrow, 1990; Morrow, Bower, \& Greenspan, 1989). They also infer distance in the models they construct, and their inferences depend on what is known about object size and rate of travel (Morrow \& Clark, 1988; see also Black, Turner, \& Bower, 1979; Glenberg, Meyer, \& Lindem, 1987; Zwaan \& Radvansky, 1998).

While building a spatial model, people even direct their gaze to where they would look if they were examining an actual scene. For instance, in a study by Spivey and Geng (2001), participants listened to stories about spatial scenes while they looked at a blank screen. The stories were not about motion per se, but they directed the participants' attention to different regions in verbally depicted scenes - for instance, to low or high floors of a tall apartment building. When the story described an object or activity on a lower floor of the building, eye movements remained low on the screen. As the description "moved" up the building, so did saccades (see also Spivey, Tyler, Richardson, \& Young, 2000).

In the studies mentioned so far, people actually moved, imagined moving, or directed their attention to areas in a mentally construed scene. But perhaps more compelling evidence for the ubiquity of mentally simulated motion is found in research that targets implicit motion. In a study on interpreting implied motion in static images, Freyd (1983) showed people pairs of photographs of actions that unfolded in time and asked them to judge whether the two photographs were the same or different. In some cases, people first saw a photograph depicting the beginning of an action-for instance, a person starting to jump off a wall (e.g., a few inches below the wall) - and then a photograph of the same person a few frames later (e.g., just above the ground). In other cases, people saw pictures in reverse order. When they viewed the pictures in a (normal) forward temporal order, they were slower to indicate a difference than when they viewed them in backward temporal order, suggesting that simulation naturally proceeds forward in the interpretation of implied motion. In other work by Kourtzi and Kanwisher (2000), participants looked at still photographs while in an fMRI scanner. They examined pictures of implied motion (e.g., an athlete with an arm in the air as if preparing to throw a ball) and of no implied motion (e.g., an athlete with arm down). Overall, there was stronger fMRI activation in MT/MST (areas associated with visual processing of motion) with implied motion than with no implied motion, suggesting that processing implied motion in static scenes is not unlike processing the perception of real motion (see also Zwaan, Madden, Yaxley, \& Aveyard, 2004, for research on the interpretation of implied motion in static images in the context of literal motion language).

\section{Fictive Motion}

Does mental simulation generalize to an even more implicit type of motion, one claimed to arise with figurative language? To be precise, what about the following type of sentences?

\section{1a. The road runs along the coast.}

\section{1b. The trail goes from El Portal to Yosemite.}

This type of sentence communicates a stationary situation even though it features a motion verb (e.g., run or go) and describes a scene that invites motion. For instance, people, vehicles, animals, or other mobile entities could easily travel along a road or a trail. Thus, unlike the literal uses of motion verbs, such as John runs along the coast, or their metaphorical uses, such as The meeting runs past midnight, fictive motion sentences communicate no change of state (Matlock, 2001). This sort of language is pervasive across languages, including English, Spanish, Hebrew, and Japanese, and it often occurs when people are describing physical space (Matlock, 2004; Matsumoto, 1996).

Despite the apparent static disposition of sentences such as 1a and 1b, Talmy $(1983,1996,2000)$ has argued that they include an implicit, "fleeting" type of motion called fictive motion (see also Langacker, 1986, 1987; Matsumoto, 1996). ${ }^{1}$ On this view, the conceptualizer (speaker or listener) takes a perspective in the scene and mentally simulates "movement" or "visual scanning" along the figure. In that simulation, the figure, often a path such as the road in Sentence 1a or a linearly extended entity (e.g., table, as in The table runs along the wall), is conceptually primary and is construed relative to a landmark or set of landmarks in an imagined spatial scene. In Sentence 1a, for example, "movement" proceeds along some portion of a road aligned with a coastline, and in Sentence 1b, from one point on a trail to another on that trail. According to Talmy (2000), fictive motion allows the conceptualizer to subjectively impose a state change on what is otherwise understood as a stationary scene. It also helps compute information about the layout of the scene, especially about the figure's location relative to the ground (see also Langacker, 2000).

Many linguistic observations lend support to the idea that fictive motion involves simulation of motion or visual scanning. Fictive motion sentences frequently incorporate words and phrases that communicate physical movement - for instance, duration, such as for $10 \mathrm{~min}$ utes in The road runs along the coast for 10 minutes, and direction, such as north in The road runs north. They also occur with manner verbs that communicate fast or slow motion in their literal uses, such as race in The freeway races past the city or crawl in Interstate 5 crawls through Los Angeles. These sentences also express unidirectional extension from one part of a scene to another, as in A scar extends from his knee to his ankle or The garden hose runs from the faucet to the flowerbed (see Langacker, 2005; Matlock, 2004, in press).

On another view, however, fictive motion sentences are said to involve no simulated motion and no state change. Jackendoff (2002, p. 362), for instance, argues that sentences such as The road runs along the coast are associated with a static representation. On this view, the path (e.g., road) constitutes an atemporal relation whereby all points along it are activated simultaneously. In this way, the rep- 
resentation underlying The road runs along the coast is not unlike that underlying The road is near the coast.

\section{Does Fictive Motion Involve Mentally Simulated Motion?}

Taken together, the research on mental simulation suggests that people (1) construct models that resemble physical space, (2) simulate objects and movement in these spatial models, and (3) simulate in a way that is to some extent analogous to perceiving physical movement. Given this, simulation might also be involved in fictive motion processing, including sentences such as The road runs along the coast or The trail goes through the desert. For instance, if people read a story about travel through a spatial region, such as a desert, they ought to construct a model with properties consistent with what they know about deserts. That model might include a flat, barren terrain. It might include a traversable path, such as a road or a trail, depending on whether the story mentioned driving or walking. It might include details about how motion transpires, such as quickly or slowly. If people read a fictive motion sentence at the end of the story, such as The trail goes through the desert, their processing ought to be affected by the model they constructed, including motion in that model. Reading about slow motion should result in longer processing times than reading about fast motion. The same should occur when people are reading about long distance (vs. short distance) and when reading about a difficult terrain (vs. an easy terrain).

Four reading experiments tested the hypothesis that the processing of fictive motion includes simulating motion. The experiments were conducted to investigate whether engaging in thought about motion or certain spatial layouts would affect the understanding of sentences such as The trail goes through the desert. In each task, participants read a story about a protagonist traveling through a spatial region and then decided whether a target fictive motion sentence (hereafter, an FM sentence) related to the story. The rationale was that the participants would first construct a spatial model while reading about a protagonist moving through physical space. In constructing the model, they would simulate motion along a path, and that simulation would be to some extent analogous to the way they would perceive or enact motion along a real path (e.g., "moving" slowly vs. quickly or a far distance vs. a short distance). Later, in deciding whether a target sentence related to the story, the participants would have to tap into the information they had constructed. If fictive motion processing involves simulation, there should be differences relating to how the motion was enacted in the story. Reading times should reflect these differences.

\section{EXPERIMENT 1 Travel Distance}

Experiment 1 was conducted to investigate whether people simulate motion when attempting to understand FM sentences, such as The road runs through the valley. The participants read a story about a protagonist travel- ing a long or a short distance and then decided whether a critical FM sentence related to the rest of the story. If fictive motion processing involves simulation, decision times for FM sentences should be longer after the participants had thought about long-distance travel.

\section{Method}

Participants. Fifty-nine undergraduates volunteered for partial credit in a psychology course at the University of California, Santa Cruz (UCSC). In this experiment and all the others, the participants were native English speakers or highly proficient bilinguals who had learned English before age 7.

Materials. The stimuli included stories and FM sentences. The 16 stories, which were an average of 10.5 lines, were about protagonists traveling through outdoor regions. The first line told the participants to imagine a region (e.g., Imagine a desert). Subsequent lines provided details about (1) the region, such as size and dimension (e.g., 400 miles in diameter), (2) a traversable path, such as a road (e.g., There is a road in the desert, It is called Road 49), (3) a moving protagonist (e.g., Today Maria is driving to her aunt's house, She is driving on Road 49), and (4) travel time (e.g., It takes her over 7 hours). Half the stories were about vehicular transportation (e.g., driving), and half were about nonvehicular travel (e.g., walking or cycling). Each story was in the present tense to accentuate the ongoing, unfolding nature of events (Langacker, 1987), and each mentioned third-person protagonists (e.g., Maria or she). Two story versions were generated, one about long-distance travel (e.g., driving 100 miles) and one about short-distance travel (e.g., driving 20 miles). Both had the same number of lines, the same mode of travel, and the same spatial region.

Sixteen FM sentences served as target sentences (e.g., Road 49 crosses the desert). All were in the present tense and featured an inanimate subject noun phrase that referred to a traversable path, such as Road 49 or bike path. Each included one of four motion verbs: go, run, cross, and follow. Two verbs, cross and follow, take a direct object (e.g., The bridge crosses a dry river bed), and two, run and go, take an indirect object (e.g., A dirt trail runs from Bird Lake to Eagle Peak). These verbs were chosen because they express no manner in their literal interpretations (vs. manner verbs, such as meander or race).

Prior to the experiment, a norming study was conducted to determine which motion verbs were manner neutral, focusing on speed, a critical component of manner of movement. Eighteen participants rated 45 verbs (e.g., shove, slide, and run) on how quickly they imagined themselves doing the actions. A rating of 7 indicated very fast, and a rating of 1 not very fast. After the norming study, cross, follow, run, and go were chosen for FM sentence stimuli in Experiment 1 (and the other experiments) because their average ratings fell in the middle range. A second norming study was done to collect ratings on time duration. The participants judged the same action words on how long they imagined it would take to do the action. A rating of 7 indicated a very long time, and a rating of 1 indicated not very long time. Overall, the results were consistent with the speed norming study. The mean ratings for cross, follow, run, and go fell in the middle range - namely, between 3 and 5. A third norming study demonstrated that each FM sentence matched both story versions equally well. Ten participants rated 16 long-distance, 16 short-distance, and 16 filler scenarios (FM sentence and story) on a scale from 1 to 7 , where 7 indicated very good match and 1 indicated very poor match. The mean ratings were consistently high: 6.63 for long distance and 6.38 for short distance. This norming study was repeated in all the other experiments.

Two sets of stories were created so no participant would see both versions. One contained half the long-distance stories and half the short-distance stories, and another contained the remaining stories. In addition to the 16 primary scenarios, these sets each contained 16 filler scenarios, including travel stories and target sentences about travel or location, such as Joe takes a bus to the farm or 
Kenora is located in the mountains. FM sentences were written so a correct answer would be yes, and filler sentences were written so a correct answer would be no. See the sample stimuli in the Appendix.

Procedure. The participants filled out a questionnaire about language background, handedness, and visual impairments. Then they sat at a computer and went through the experimental instructions, which informed them that they would be reading stories and answering questions. The instructions also included an example of a story with a critical sentence that was related and one that was not related. The participants were encouraged to read quickly but to imagine what they read. They completed four practice trials, during which time they received immediate feedback about whether their answers were correct. After the practice trials, the experimenter asked if the instructions were clear. If the participant gave an affirmative response and had no questions, the participant was instructed to proceed to the experiment.

The noncritical story sentences appeared one line at a time on the screen. Each participant pressed any key to advance to the next sentence. A new trial began with the prompt "Ready?" at which time the participant pressed any key to see * and then any key to see the first sentence of the story. At the end, the line "Next sentence related to story: Yes or no?" informed the participant that the test sentence would be next. After pressing any key, the participant read the test sentence and decided whether it related to the story. A green yes buttonpress ("k" key) was an affirmative response, and a red no buttonpress ("d" key) was a negative response. Next the participant saw *, which marked the end of the trial, and then pressed any key to see "Ready?" again. This procedure was repeated for every scenario. Most participants took 20-30 min to complete the experiment.

The experiment was run on a PC with a 17-in. monitor. SuperlabPro Experimental Laboratory Software randomly ordered scenarios and recorded decision times (time from one keypress to the next) in milliseconds. A correct response was yes to an FM sentence, and an incorrect response was no or a wrong keypress (e.g., the space bar). Only yes responses were recorded.

\section{Results and Discussion}

Data from 11 participants were discarded, 2 because of computer problems and 9 because of error rates over $25 \%$. In this experiment and the others, that high an error rate indicated that the participant was not paying attention or did not understand the instructions. Next, FM sentence decision times over $8,000 \mathrm{msec}$ or below $500 \mathrm{msec}$ were removed (of all the responses, $2.5 \%$ long, $2 \%$ short). A score over $8,000 \mathrm{msec}$ was an extremely long time to respond and suggested that the participant was momentarily distracted or confused. A score of $500 \mathrm{msec}$ or lower was an extremely short time and suggested that the participant accidentally hit the response key or did not spend sufficient time to process the sentence. In this experiment and all the others, scores above $8,000 \mathrm{msec}$ and below $500 \mathrm{msec}$, in addition to outliers, were removed because they reflected an unreasonable amount of time to make a decision about a critical sentence. After that, all the outliers were omitted (3\% long, $2.5 \%$ short). An outlier was a score that fell above or below $2 S D$ s of the mean calculated across participants for every item. After data cleaning, error rates were $5 \%$ for short distance and $6 \%$ for long distance (of all the responses). (From this point on, percent designates percentage of all responses.) In this and the other experiments, only scores for correct decisions were analyzed, once in a participant analysis $\left(t_{1}\right)$ and once in an item analysis $\left(t_{2}\right)$.
Overall, people took 409 msec longer ( $M=3,711$, $S D=804$ ) to make a decision about an FM sentence after reading about long-distance travel than they did after reading about short-distance travel $[M=3,302, S D=875$; $\left.t_{1}(47)=2.70, p<.005 ; t_{2}(15)=2.79, p<.02\right]$, indicating that fictive motion processing was influenced by the way people thought about distance. In particular, after reading about a protagonist traveling a long distance, people were slower to make a decision about an FM sentence.

One explanation for the latency differences here is that the readers constructed a spatial model and imagined movement through that model while reading about travel. Later, they simulated movement along the path in a way that was consistent with the protagonist's movement along that path. For instance, in attempting to understand and decide whether Road 49 crosses the desert related to the story, people simulated motion along the road they had imagined. When they had thought about a protagonist traveling a long distance on that road, the FM sentence about Road 49 took longer to process than it did with a short distance.

However, could it be that something other than simulation led to the differences in Experiment 1? What about linguistic priming? Perhaps subtle variations in the linguistic content alone-words about short-distance and long-distance travel-brought on differences in latencies. Maybe reading language such as over 7 hours, as in It takes her over 7 hours to get to her aunt's house, made people slower to read and to make a decision about critical sentences than did reading language such as only 20 minutes, as in It takes her only 20 minutes to get to her aunt's house.

A follow-up control study tested whether the same differences would arise with literal sentences about paths (e.g., road). If the latency differences in Experiment 1 were the result of linguistic priming alone, we should see the same differences with nonfictive motion sentences.

\section{Control Study}

In the control study, 124 participants read the same stories and did the same task, but this time, the critical sentences were different. They did not include fictive motion, but they were similar in meaning (i.e., they described the same static scenes and the same paths). A norming study was conducted to check whether the new critical sentences were similar in meaning to the original FM sentences. Eleven participants rated pairs of sentences on a scale from 1 to 7 (not at all similar vs. very similar). The pairs included the original FM sentence, such as Road 49 crosses the desert, and a new nonfictive motion spatial sentence, such as Road 49 is in the desert. The mean rating was 5.98, which showed that overall, the sentences were judged as very similar in meaning. (The same norming study was used in control studies for Experiments 2 and 3.) An example of a control sentence with a story is shown in the Appendix.

In this control study, data were removed for 21 participants, 3 for computer problems, and 18 for error rates over $25 \%$. Data cleaning removed FM sentence latencies over 8,000 msec and below $500 \mathrm{msec}$ (3\% long, 3\% short) 
and all outliers ( $1 \%$ long, $1 \%$ short). The error rates were $7.5 \%$ for long and $7.5 \%$ for short. People took $28 \mathrm{msec}$ longer to read nonfictive motion sentences after reading about long-distance travel $(M=3,806, S D=906)$ than after reading about short-distance travel $(M=3,778, S D=$ $832)$, but the difference was not significant $\left[t_{1}(102)=\right.$ 0.34 , n.s.; $t_{2}(15)=0.58$, n.s.].

Next, a power analysis was necessary to determine whether the lack of a reliable difference in the control study was the result of insufficient power. For this analysis, an effect size of .38 was used-namely, the effect size of the difference between latencies for FM sentences in the short-distance and the long-distance conditions in Experiment 1. The power of detecting a difference of size .38 was .97 , given a sample size of 103 and an alpha of .05. This analysis shows that the lack of a reliable difference in the control study was not the result of low power. Critically, the control study showed that people were no slower to read a nonfictive motion spatial sentence when reading about long-distance travel than when reading about short-distance travel. This shows that the differences in Experiment 1 were not the result of word priming alone.

\section{EXPERIMENT 2 Travel Rate}

Experiment 1 showed that people were slower to read FM sentences after stories about long-distance travel than after stories about short-distance travel. With the same paradigm, Experiment 2 was conducted to investigate whether differences would arise after stories about slow or fast motion. If people simulate motion while attempting to understand FM sentences, those sentences should be processed more quickly after they read about fast travel than after they read about slow travel.

\section{Method}

Participants. Fifty-four UCSC undergraduates participated for credit in a psychology course.

Materials. The critical sentences were 16 FM sentences, such as The highway runs through the valley. These sentences included the verbs from Experiment 1 and were paired with travel stories. The stories, which had an average of 11 lines, had two versions. Fasttravel stories highlighted fast travel (e.g., driving $100 \mathrm{mph}$ ), and slow-travel stories highlighted slow travel (e.g., driving $40 \mathrm{mph}$ ). The descriptions of the automobiles varied (e.g., a Ferrari vs. a VW bus), and so did the descriptions of the protagonists in nondriving stories (e.g., an athletic vs. an out-of-shape hiker).

A norming study was conducted to determine whether all the scenarios were well matched. As in Experiment 1, 10 participants rated FM sentences and stories. Average ratings were high: 5.72 for fast travel and 5.69 for slow travel. Two sets of scenarios were created, one containing 8 fast-travel stories and 8 slow-travel stories, and the other containing the remaining 16 stories. Both sets had the same 16 filler scenarios. Examples are shown in the Appendix.

Procedure. The procedure was identical to that in Experiment 1.

\section{Results and Discussion}

Data from 7 participants were discarded, 2 because of computer problems and 5 because of error rates over $25 \%$.
Scores above $8,000 \mathrm{msec}$ and below $500 \mathrm{msec}$ (1\% slow, $1 \%$ fast) were eliminated, and so were outliers ( $3 \%$ slow, $3 \%$ fast). Error rates were $7 \%$ for fast and $7 \%$ for slow.

Overall, people took $391 \mathrm{msec}$ longer to read FM sentences after stories about slow travel $(M=3,142, S D=$ 650) than they did after stories about fast travel $[M=$ $2,745, S D=587 ; t_{1}(46)=4.02, p<.001 ; t_{2}(15)=4.33$, $p<.001$ ], suggesting that fictive motion processing was influenced by the way they thought about movement in the story. Specifically, when people read about a protagonist moving slowly, they were slower to read and make a decision about an FM sentence.

One explanation for these results is that the readers constructed a model that included fast or slow movement along a path while they read a story. Later, while attempting to understand the FM sentence, they simulated movement in a way that was consistent with the way the protagonist had moved. Perhaps, however, the differences were the result of some kind of priming. For instance, the language in the fast-travel condition, such as He is running (vs. language in the slow-travel condition, such as He is walking), may have made it easier to understand critical FM sentences. A control study was conducted to investigate this possibility.

\section{Control Study}

In the control study, 122 participants read Experiment 2 stories and did the same task, but instead of reading FM sentences, they read comparable nonfictive motion target sentences (see the norming study in the control study in Experiment 1). A norming study was conducted to determine whether the new sentences were semantically similar. Eleven participants rated the pairs of sentences (see the control study, Experiment 1), and the mean rating was 6.24 , showing high similarity. The objective was to see whether the same results would be obtained with comparable nonfictive motion sentences. If no differences arose, we could rule out the influence of linguistic priming alone. See the Appendix for an example of a control sentence with a story.

Prior to the analysis in this control study, data from 13 participants were discarded, 2 because of computer problems and 11 because of error rates over $25 \%$. Of the remaining data, scores above $8,000 \mathrm{msec}$ and below $500 \mathrm{msec}$ were discarded ( $1 \%$ fast, $1.5 \%$ slow), and so were outliers ( $1.5 \%$ fast, $1.5 \%$ slow). Overall, the error rates were $6 \%$ for slow and $6 \%$ for fast. Latencies for nonfictive motion sentences were $65 \mathrm{msec}$ longer after a slow-travel story $(M=3,213, S D=799)$ versus after a fast-travel story $(M=3,148, S D=769)$, but the difference was not reliable $\left[t_{1}(108)=1.01\right.$, n.s.; $t_{2}(15)=0.26$, n.s. $]$. These results show that the information in the stories did not influence the processing of the FM sentences.

A power analysis checked whether the lack of a significant difference was due to insufficient power. An effect size of .51 was used, which was the size of the difference between fast travel and slow travel in the main experiment. Given a sample size of 109 with an alpha of .05 , the power of detecting the effect size of .51 was .99 . 
Hence, the failure to detect an effect of rate of travel in the control experiment was not the result of low power. Critically, the control study shows that people were no slower to read a nonfictive motion spatial sentence when reading about slow travel than they were when reading about fast travel. The results show that the differences in Experiment 2 did not occur merely because of linguistic priming.

\section{EXPERIMENT 3 Terrain}

The first two experiments showed that reading about short- or long-distance travel or about slow or fast travel affected the processing of FM sentences, such as The highway runs through the valley. In both cases, the focus was on the path (speed or distance) along which the protagonist traveled. Experiment 3 focused on terrain through which the path extends. Of interest here was whether terrain would influence fictive motion processing. This time, the participants read stories about travel through difficult terrain or easy terrain. Difficult-terrain stories highlighted information associated with slow or impeded travel, such as rugged and rocky deserts, and easy-terrain stories highlighted information about rapid or unimpeded travel, such as flat and level deserts. If fictive motion involves simulated motion, the way people imagine movement through a terrain should affect their understanding of a subsequent FM sentence. Latencies for FM sentences should be shorter after people read about easy travel.

\section{Method}

Participants. Eighty-one UCSC undergraduates participated for credit in a psychology course.

Materials. The target sentences were $16 \mathrm{FM}$ sentences, such as $A$ road follows the coast all the way around the island. These sentences included the verbs from Experiments 1 and 2 and appeared with two versions of travel stories, including difficult travel and easy travel. Both versions had an average of nine lines and featured the same protagonist but differed on terrain. For instance, a difficultterrain desert was described as rocky or riddled with gullies, and an easy-terrain desert was described as smooth and level. A norming study with 9 participants ensured that the FM sentences were well matched with both versions of the stories. The average ratings were 6.01 for difficult terrain and 6.03 for easy terrain. Primary stimuli were divided into two sets. One set contained 8 easy-terrain stories and 8 difficult-terrain stories, and another contained the remaining 16 stories. Both sets had the same 16 filler stories and target sentences. See sample stimuli in the Appendix.

Procedure. The procedure was the same as that in Experiments 1 and 2 .

\section{Results and Discussion}

Data from 7 participants were removed, 1 because of computer problems and 6 because of error rates over $25 \%$. Scores above $8,000 \mathrm{msec}$ and below $500 \mathrm{msec}$ were removed ( $1 \%$ easy, $1 \%$ difficult), as were outliers $(4 \%$ easy, $4.5 \%$ difficult). The error rates were $5 \%$ for easy terrain and $6 \%$ for difficult terrain.

Overall, the participants took $337 \mathrm{msec}$ longer to read FM sentences with stories about difficult terrain $(M=$
$2,768, S D=431)$ versus stories about easy terrain $[M=$ $2,584, S D=398 ; t_{1}(73)=3.12, p<.003 ; t_{2}(15)=2.41$, $p<.03$ ], indicating that fictive motion processing was affected by the way people had thought about travel. Namely, when people read about movement through easy terrain, they processed a related FM sentence more quickly.

One explanation for these differences is that while people were reading the story, they constructed a model, including a path and motion along that path. Next, while attempting to understand and make a decision about the FM sentence, they simulated motion along the path in a way that was consistent with the way the protagonist had moved. For instance, when people imagined a person driving on a road along a smooth, flat shoreline, they simulated motion more quickly than when they had imagined driving on a road along a rugged shoreline. Alternatively, the differences could be the result of word priming. Something about the language in the easy-terrain stories, such as smooth and flat (vs. the language in difficult-terrain stories, such as rugged and jagged) may have made it easier to understand the critical sentences, such as $A$ road runs along the peninsula. The follow-up control study was conducted to investigate this possibility.

\section{Control Study}

In this study, 125 participants read the same Experiment 3 stories, but this time, they read different target sentences. These new target sentences were comparable, but they did not have a fictive motion interpretation (see the norming study in the Experiment 1 control study). If the same results were obtained in this control study, we could rule out the possibility that the differences in Experiment 3 were due to word priming. A norming study was conducted to determine whether the new sentences were semantically similar. Eleven participants rated the pairs of sentences (see the control study, Experiment 1), and the mean rating was 5.76, showing high similarity. See the Appendix for an example of a control sentence.

In the control study, data from 18 participants were discarded, 3 because of computer problems and 15 because of error rates over $25 \%$. Scores above $8,000 \mathrm{msec}$ and below $500 \mathrm{msec}$ were removed ( $1 \%$ easy, $1 \%$ difficult), and so were outliers (1.5\% easy, $1.5 \%$ difficult). Overall, people took $78 \mathrm{msec}$ longer to read a nonfictive motion target sentence after a story about travel through difficult terrain $(M=2,643, S D=692)$ than they did after a story about travel through easy terrain $[M=2,565$, $S D=709 ; t_{1}(104)=1.57$, n.s.; $t_{2}(15)=1.07$, n.s. $]$. The error rates were $5 \%$ for difficult terrain and $5 \%$ for easy terrain.

A power analysis was conducted to determine whether the lack of a reliable difference in the control study was the result of insufficient power. For this analysis, an effect size of .79 was used-namely, the size of the difference between the easy-terrain and the difficult-terrain conditions in Experiment 3. Given a sample size of 105 and an alpha of .05, the power of detecting this effect size was .99. Therefore, the failure to detect any effect in the control experiment was not because of low power. Im- 
portantly, the control study showed that people were no slower to process a nonfictive motion spatial sentence after reading about difficult travel terrain than after reading about easy travel terrain, ruling out the possibility that the differences in Experiment 3 were the result of priming.

\section{EXPERIMENT 4 Type 2 Fictive Motion}

Experiments 1-3 showed shorter latencies for FM sentences when travel along a path had been described as involving a short distance, fast movement, or an easy terrain. None of the FM sentences in those experiments had mentioned any explicit motion, but all were instances of Type 1 fictive motion. In Type 1 fictive motion, the subject noun phrase referent is metonymically associated with motion. For instance, in The trail runs through the woods, the noun trail is associated with hiking or walking, or in The road goes along the property line, the noun road is associated with driving. In Type 2 fictive motion, also prevalent in English, the subject noun phrase referent is not associated with motion. Rather, it is a nontraversable linear or spatially extended object, such as fence, as in The fence runs along the coastline, or table, as in The table goes from this wall to that wall (see Matlock, 2004).

Experiment 4 was conducted to investigate the comprehension of Type 2 fictive motion. It targeted FM sentences such as $A$ fence follows the property line and The earthquake fault runs across the valley. Of interest was how people would process FM sentences with no traversable path and no association with motion, especially after reading stories not about travel. How would people process Type 2 FM sentences after stories about difficult terrains (e.g., cluttered or uneven) and easy terrains (e.g., uncluttered or flat)? Would it take longer to process a Type 2 FM sentence after they had read about a difficult terrain? Such a result would lend support to the claim that people simulate not just movement, but also visual scanning, in processing fictive motion (Langacker, 2000; Talmy, 2000). That is, people scan along a figure or the prominent linear entity to which the subject noun phrase refers - for instance, a fence, as in The fence follows the property line. Such a result would also suggest that simulation is not restricted to fictive motion that indirectly implies physical motion; rather, it generalizes to fictive motion that implies no motion at all.

\section{Method}

Participants. Forty-four UCSC undergraduates participated for credit in a psychology course.

Materials. As in the other experiments, there were two versions of all 16 travel stories: an easy-terrain story and a difficult-terrain story. However, unlike the stories in the other experiments, the stories did not highlight a travel path or a moving protagonist. Each story had an average of seven lines. The 16 FM sentences featured the manner-neutral motion verbs go, run, cross, and follow from Experiments 1, 2, and 3. These verbs were chosen from the norming studies in the previous experiments. A norming task with 9 par- ticipants determined whether stories and FM sentences in both conditions were relatively equally well matched. The mean ratings were 5.92 for difficult terrain and 6.05 for easy terrain. See the Appendix for sample stimuli.

Procedure. The procedure was the same as that in Experiments 1, 2 , and 3 .

\section{Results and Discussion}

Five participants' data were discarded because they contained over $25 \%$ errors. Scores above $8,000 \mathrm{msec}$ and below $500 \mathrm{msec}$ were removed ( $1 \%$ easy, $1.5 \%$ difficult), and so were outliers ( $2 \%$ easy, $2 \%$ difficult). The error rates were $4 \%$ for easy terrain and $5.5 \%$ for difficult terrain.

Overall, the participants took $213 \mathrm{msec}$ longer to read and make a decision about an FM sentence after reading about a difficult terrain $(M=2,698, S D=693)$ than they did after reading about an easy terrain $[M=2,485$, $S D=522 ; t_{1}(38)=2.15, p<.04 ; t_{2}(15)=2.74, p<$ $.02]$, indicating that terrain influenced fictive motion latencies. Namely, after reading about a nontraversable linear figure (e.g., a fence) in a difficult terrain, people were slower to process a Type 2 FM sentence about that figure.

These results suggest that simulation is included in Type 2 fictive motion. They lend support to the idea that people mentally simulate visual scanning while processing sentences that have no association with motion.

\section{GENERAL DISCUSSION}

Four experiments were conducted to investigate whether mental simulation underlies the comprehension of fictive motion language. Of interest was whether reading and thinking about travel through a spatial region would influence the comprehension of an FM sentence, such as The road runs along the coast, a spatial sentence that communicates no explicit motion but has been associated with an implicit, imaginary type of movement (e.g., Talmy, 1996). In all the experiments, fictive motion decision times were influenced by the way motion (or spatial configuration in Experiment 4) had been described. Latencies were shortest after short distance (Experiment 1), fast motion (Experiment 2), and uncluttered terrain (Experiment 3). All these cases involved Type 1 FM sentences, whereby the subject noun phrase referent (e.g., road) was associated with movement (e.g., driving on a road). But the same effect was also observed in Experiment 4 with Type 2 FM sentences. In those cases, the subject noun phrase referent had no association with motionfor instance, fence in The fence runs across the property line. These consistent differences were not the result of linguistic priming alone, for the control studies (Experiments 1,2 , and 3 ) showed no differences for nonfictive motion target sentences.

Overall, the results suggest that fictive motion involves simulation. In all the experiments (except Experiment 4), decision times for FM sentences varied according to movement and travel in the stories. For instance, in Experiment 1 , if the travel was long distance, the fictive 
motion decision times were long, and in Experiment 2, if the travel was fast, the fictive motion decision times were fast, and so on. The results may not seem surprising, given that people take longer to mentally "move" from one place to another when the imagined places are believed to be far apart (e.g., Denis \& Cocude, 1989; Kosslyn, Ball, \& Reiser, 1978) or that they judge distances between moving entities and landmarks as greater when the moving entity is believed to be moving quickly (e.g., Morrow \& Clark, 1988). But what makes the findings discussed here novel is that the target sentences communicate no explicit movement. There is no real movement with The road runs along the coast, for the road does not move and neither does the coast. The lack of motion is especially apparent in Experiment 4, which targeted Type 2 fictive motion.

Taken together, the results suggest that mental simulation does generalize to a more implicit type of motionnamely, one involved in the understanding of motion verbs in nonliteral uses. However, several questions deserve further attention. First, what does it mean to simulate motion while processing a sentence such as The road runs along the coast? One possibility is that people (1) first reactivate a static linear or path-like model (e.g., a road or a trail) on the basis of what they have just read and (2) later simulate movement along that path. A second possibility is that fictive motion involves gradually constructing a path or linear representation. For instance, in reading about and imagining a road running along a coast, people incrementally build a road next to a coastline, beginning at one point, continuing to the next point, and then to the next, and eventually stopping. A third possibility is that it is not motion or scanning that is simulated per se but, rather, a state change. That is, in construing The road runs along the coast, the person momentarily imagines one point along the road and then, milliseconds later, imagines another point along the road. The three explanations are not necessarily mutually exclusive: People may combine these types of simulations, especially in natural discourse. In any event, the data here do not distinguish among these.

Second, is there any other explanation? So far, the argument has been that the participants mentally simulated motion while processing FM sentences. Some might argue that the differences obtained here were due to semantic incongruity - in particular, incongruity of the motion verb in the target sentence with the motion in the story. Consider Experiment 3, in which a protagonist moved through difficult terrain or easy terrain. Perhaps, reading about movement through difficult terrain made it harder to understand an FM sentence (especially with a verb such as run or cross, because they often denote straight or direct motion) and that incongruity made for a longer decision time. For one thing, all the FM sentences and all the stories were normed on how well they went together (prior to each experiment). This should have eliminated any obvious incongruities. For another, how could this explain Experiment 4, in which the participants read FM sentences after stories with no mo- tion? Semantic incongruity alone cannot adequately explain that difference, because there is no explicit motion for the motion verb to be congruent or incongruent with. At any rate, semantic congruity and simulation are not necessarily mutually exclusive. The challenge is to find the right task to obtain a better measure of what is happening during fictive motion processing, or to find a task that employs nonlinguistic primes.

Finally, although the results suggest that simulation occurs when people are attempting to comprehend the meaning of FM sentences, the task is not sufficiently sensitive to determine precisely what is happening during sentence processing. For instance, if people read about slow motion and simulate motion while processing a sentence such as The road goes along the coast, when does that simulation start? When does it end? When does it slow down or speed up? At the verb, or some place downstream? A more sensitive task (e.g., cross-modal priming or a dual task) could provide a better idea about what is happening during a simulation. In the same vein, what is happening moment to moment while people are constructing these spatial models from the reading of travel stories? Do space and time independently contribute to how people simulate motion along a path in one of these models? Do they contribute equally? Or does temporal information play a more robust role (see Zwaan \& Radvansky, 1998, for a discussion of the primacy of time in situation models)?

In sum, this research explored the relationship between thought about motion and language about motion - in particular, figurative language about motion. The results suggest that people simulate motion or visual scanning while trying to understand FM sentences such as The road runs along the coast. The effect was robust and arose under various circumstances. The results present a challenge to models that favor purely static representations for this type of language (Jackendoff, 2002) and call for some kind of dynamic representation (Matlock, Ramscar, \& Boroditsky, 2003). More generally, the work goes against purely amodal or symbolic approaches to language (see Barsalou, 1999b, 2003; Stanfield \& Zwaan, 2001), which would predict none of the outcomes observed here. Instead, the findings support many of the claims about the underlying conceptual nature of language, including tacit conceptual nature (Boroditsky \& Ramscar, 2002; Clark, 1973; Gibbs, 1994, 2004; Glenberg, 1999; Lakoff, 1987; Lakoff \& Johnson, 1999). Finally, the results have broad implications for research on figurative language and thought, because they suggest that the mental simulation of motion occurs not just in literal thought and language about motion, but in figurative thought and language about motion as well.

\section{REFERENCES}

Barbey, A. K., Simmons, W. K., Ruppert, J. A., \& Barsalou, L. W. (2002, November). Action and conceptual processing. Paper presented the 43rd Annual Meeting of the Psychonomic Society, Kansas City, MO. BARSAlOU, L. W. (1999a). Language comprehension: Archival memory or preparation for situated action? Discourse Processes, 28, 61-80. 
Barsalou, L. W. (1999b). Perceptual symbol systems. Behavioral \& Brain Sciences, 22, 577-660.

BARSALOU, L. W. (2003). Situated simulation in the human conceptual system. Language \& Cognitive Processes, 18, 513-562.

Black, J. B., TURner, T. J., \& Bower, G. H. (1979). Point of view in narrative comprehension, memory, and production. Journal of Verbal Learning \& Verbal Behavior, 18, 187-198.

BoroDITSKY, L. (2000). Metaphoric structuring: Understanding time through spatial metaphors. Cognition, 75, 1-28.

BorODITSKY, L., \& RAMSCAR, M. (2002). The roles of body and mind in abstract thought. Psychological Science, 13, 185-189.

Bower, G. H., \& Morrow, D. G. (1990). Mental models in narrative comprehension. Science, 247, 44-48.

Clark, H. H. (1973). Space, time, semantics, and the child. In T. E. Moore (Ed.), Cognitive development and the acquisition of language (pp. 27-63). San Diego: Academic Press.

DenIs, M., \& Cocude, M. (1989). Scanning visual images generated from verbal descriptions. European Journal of Cognitive Psychology, 1, 293-307.

FREYD, J. J. (1983). The mental representation of movement when static stimuli are viewed. Perception \& Psychophysics, 33, 575-581.

GibBs, R. W. (1994). The poetics of mind: Figurative thought, language, and understanding. New York: Cambridge University Press.

GibBs, R. W. (2004). Embodiment and cognitive science. New York: Cambridge University Press.

Glenberg, A. M. (1999). Why mental models must be embodied. In G. Rickheit \& C. Habel (Eds.), Mental models in discourse processing and reasoning (pp. 77-90). New York: Elsevier.

GlenberG, A. M., \& KaschaK, M. P. (2002). Grounding language in action. Psychonomic Bulletin \& Review, 9, 558-565.

Glenberg, A. M., Meyer, M., \& Lindem, K. (1987). Mental models contribute to foregrounding during text comprehension. Journal of Memory \& Language, 26, 69-83.

JACKENDOFF, R. (2002). Foundations of language: Brain, meaning, grammar, evolution. New York: Oxford University Press.

Kosslyn, S. M., Ball, T. M, \& ReISER, B. J. (1978). Visual images preserve metric spatial information: Evidence from studies of image scanning. Journal of Experimental Psychology: Human Perception \& Performance, 4, 47-60.

KoURTZI, Z., \& KANWISHER, N. (2000). Activation in human MT/MST by static images with implied motion. Journal of Cognitive Neuroscience, 12, 48-55.

LAKOFF, G. (1987). Women, fire, and dangerous things: What categories reveal about the mind. Chicago: University of Chicago Press.

Lakoff, G., \& Johnson, M. (1999). Philosophy in the flesh: The embodied mind and its challenge to Western thought. New York: Basic Books.

LANGACKER, R. W. (1986). Abstract motion. In V. Nikiforidou, M. VanClay, M. Niepokuj, \& D. Feder (Eds.), Proceedings of the Twelfth Annual Meeting of the Berkeley Linguistics Society (pp. 455-471). Berkeley: University of California, Berkeley Linguistics Society.

LANGACKER, R. W. (1987). Foundations of cognitive grammar: Vol. 1. Theoretical prerequisites. Stanford, CA: Stanford University Press.

LANGaCKer, R. W. (2000). Virtual reality. Studies in the Linguistic Sciences, 29, 77-103.

LANGackeR, R. W. (2005). Dynamicity, fictivity, and scanning: The imaginative basis of logic and linguistic meaning. In R. A. Zwaan \& D. Pecher (Eds.), Grounding cognition: The role of perception and action in memory, language, and thinking (pp. 164-197). Cambridge: Cambridge University Press.

Matlock, T. (2001). Fictive motion is real motion. Paper presented at the Seventh Annual International Cognitive Linguistics Conference, University of California, Santa Barbara.
MatLock, T. (2004). The conceptual motivation of fictive motion. In G. Radden \& R. Dirven (Eds.), Studies in linguistic motivation (pp. 221248). Berlin: Mouton de Gruyter.

Matlock, T. (in press). Depicting fictive motion in drawings. In J. Luchenbroers (Ed.), Cognitive linguistics: Investigations across languages, fields, and philosophical boundaries. Amsterdam: Benjamins.

Matlock, T., Ramscar, M., \& Boroditsky, L. (2003). The experiential basis of meaning. In Proceedings of the Twenty-Fifth Annual Conference of the Cognitive Science Society (pp. 792-797). Mahwah, NJ: Erlbaum.

Matsumoto, Y. (1996). Subjective motion and English and Japanese verbs. Cognitive Linguistics, 7, 183-226.

Morrow, D. G., Bower, G. H., \& Greenspan, S. L. (1989). Updating situation models during narrative comprehension. Journal of Memory \& Language, 28, 292-312.

MORROW, D. G., \& CLARK, H. H. (1988). Interpreting words in spatial descriptions. Language \& Cognitive Processes, 3, 275-291.

SchwarTz, D. L. (1999). Physical imagery: Kinematic versus dynamic models. Cognitive Psychology, 38, 433-464.

Schwartz, D. L., \& BLACK, T. (1999). Inferences through imagined actions: Knowing by simulated doing. Journal of Experimental Psychology: Learning, Memory, \& Cognition, 25, 116-136.

SpIVEY, M. J., \& GenG, J. J. (2001). Oculomotor mechanisms activated by imagery and memory: Eye movements to absent objects. Psychological Research/Psychologische Forschung, 65, 235-241.

SpiveY, M. J., Tyler, M., Richardson, D. C., \& Young, E. (2000). Eye movements during comprehension of spoken scene descriptions. In Proceedings of the Twenty-Second Annual Meeting of the Cognitive Science Society (pp. 487-492). Mahwah, NJ: Erlbaum.

Stanfield, R. A., \& ZwaAn, R. A. (2001). The effect of implied orientation derived from verbal context on picture recognition. Psychological Science, 121, 153-156.

TALMY, L. (1983). How language structures space. In H. L. Pick, Jr. \& L. P. Acredolo (Eds.), Spatial orientation: Theory, research, and application (pp. 225-282). New York: Plenum.

TALMY, L. (1996). Fictive motion in language and "ception." In P. Bloom, M. A. Peterson, L. Nadel, \& M. F. Garrett (Eds.), Language and space (pp. 211-276). Cambridge, MA: MIT Press.

TAlmy, L. (2000). Toward a cognitive semantics: Vol. I. Conceptual structuring systems. Cambridge, MA: MIT Press.

Tversky, B. (1996). Spatial perspective in descriptions. In P. Bloom, M. A. Peterson, L. Nadel, \& M. F. Garrett (Eds.), Language and space (pp. 463-491). Cambridge, MA: MIT Press.

TVErsky, B. (2000). Remembering spaces. In E. Tulving \& F. I. M. Craik (Eds.), The Oxford handbook of memory (pp. 363-378). New York: Oxford University Press.

Zwaan, R. A., Madden, C. J., Yaxley, R. H., \& Aveyard, M. E. (2004). Moving words: Dynamic mental representations in language comprehension. Cognitive Science, 28, 611-619.

ZwaAn, R. A., \& Radvansky, G. A. (1998). Situation models in language comprehension and memory. Psychological Bulletin, $\mathbf{1 2 3}_{2}$ 162-185.

ZWAAN, R. A., \& VAN OOSTENDORP, H. (1993). Do readers construct spatial representations in naturalistic story comprehension? Discourse Processes, 16, 125-144.

\section{NOTE}

1. My work focuses on one type of fictive motion: Talmy's (2000) coextension path fictive motion. There are many other types, including shadow emanation path, as in The statue threw its shadow across the yard, and pattern paths, as in My wet hair left a trail of water spots on the floor. 


\section{Experiment 1: Sample Stimuli}

Short Distance Scenario

Imagine a desert

From above, the desert looks round

The desert is small

It is only 30 miles in diameter

There is a road in the desert

It is called Road 49

It starts at the north end of the desert

It ends at the south end of the desert

Maria lives in a town on the north end of the desert

Her aunt lives in a town on the south end

Road 49 connects the two towns

Today Maria is driving to her aunt's house

She is driving on Road 49

It takes her only 20 minutes to get to her aunt's house

After she arrives, Maria says, "What a quick drive!"

FM sentence: Road 49 crosses the desert

Long Distance Scenario

Imagine a desert

From above, the desert looks round

The desert is large

It is 400 miles in diameter

There is a road in the desert

It is called Road 49

Road 49 starts at the north end of the desert

Road 49 ends at the south end of the desert

Maria lives in a town on the north end of the desert

Her aunt lives in a town on the south end

Road 49 connects the two towns

Today Maria is driving to her aunt's house

She is driving on Road 49

It takes her over 7 hours to get to her aunt's house

After she arrives, Maria says, "What a long drive!"

FM sentence: Road 49 crosses the desert

Control Study Sentence: Road 49 is located in the desert

Filler Scenario:

Imagine a large forest

A road winds through the forest

The road is called "Mist Road"

Mist Road is very scenic

Mist Road is over 100 miles long

It starts at Snow Peak and ends at Ned's Gulch

Today Pete is driving on from Snow Peak to Ned's Gulch

He's driving a brand new 4-wheel drive SUV

It takes Pete six hours to complete the drive

It seems like it takes forever!

Test sentence: Pete drives from Snow Peak to Planada

\section{Experiment 2: Sample Stimuli}

Slow Scenario

Peter is a 75 -year-old man

Peter has a bad heart

He has just started a walk program

Today Peter is walking in a local park

He is walking on path next to a creek

Peter slowly walks along the creek for 3 miles

At one point Peter tries to jog

Peter is barely able to get to the end of the path

$\mathrm{He}$ feels terrible and is totally exhausted 
It takes him over an hour to finish his walk FM sentence: The path follows the creek

\section{Fast Scenario}

Peter is a 25-year-old athlete

Peter is in excellent shape

He frequently runs to keep in shape

Today Peter is jogging in a local park

He is running on a path next to a creek

Peter runs quickly along the creek for 3 miles

Sometimes Peter even sprints along the creek

Peter quickly reaches the end of the trail

He feels great and is totally exhilarated

It takes him only 15 minutes to do the run

FM sentence: The path follows the creek

Control Study Sentence: The path is next to the creek

\section{Filler Scenario}

Imagine a park

There's a dry river bed there

There's a path next to the river

People often hike on the path

Or sometimes they use it for mountain biking

Today Paul is hiking on the path

He's hiking at a moderate pace

He hikes all the way to Big Bend Point

Then he comes back to his car

The whole trip takes seven hours

What a long hike!

Test sentence: Paul bikes all the way to Big Bend Point

\section{Experiment 3: Sample Stimuli}

Difficult Scenario

Imagine a peninsula

It is 30 miles long and 5 miles wide

The shoreline of the peninsula is very rugged

There is a scenic road along the shore

Bob is driving the entire length of the peninsula

There are many hairpin turns

Bob drives past many jagged cliffs

FM sentence: A road runs along the peninsula

\section{Easy Scenario}

Imagine a peninsula

It is 30 miles long and 5 miles wide

The shoreline of the peninsula is smooth and flat

There is a scenic road along the shore

Bob is driving the entire length of the peninsula

The road is straight and level

Bob drives past many white sandy beaches

FM sentence: A road runs along the peninsula

Control Study Sentence: There is a road along the peninsula

\section{Filler Scenario}

Imagine a lake

It measures 5 miles by 5 miles

There's a popular campground at the lake

A lot of people go fishing there

Doug is a truck driver

He's camping at the lake with his family

The ground around the lake is rugged

The road that circles the lake is bumpy

It's called "Lake Road"

Trucks are not allowed on Lake Road 
It's narrow and windy

Test sentence: Doug drives his 18-wheel truck around the lake

\section{Experiment 4: Sample Stimuli}

Difficult Scenario

Imagine an earthquake fault

The earthquake fault is in a large valley

The valley is 100 miles long and 100 miles wide

The earthquake fault is 100 miles in length

It starts at one end of the valley

It ends at the other end

The fault is very straight

The fault goes in a north-south direction

FM sentence: An earthquake fault runs across the valley

Easy Scenario

Imagine an earthquake fault

The earthquake fault is in a large valley

The valley is 100 miles long and 100 miles wide

The earthquake fault is 100 miles in length

It starts at one end of the valley

It ends at the other end

The fault zigzags back and forth

In some spots, bushes are growing in the fault

FM sentence: An earthquake fault runs across the valley

(Manuscript received September 9, 2003;

revision accepted for publication April 23, 2004.) 